\title{
LA "COLONIALIDAD DEL SER" EN LOS DISCURSOS ILUSTRADOS SOBRE EL CUERPO INDÍGENA AMERICANO
}

MARÍA TERESA GUERRERO BUCHELI ${ }^{1}$

UNAM

RESUMEN: El presente artículo tiene como propósito presentar de manera general algunos avances de la recopilación historiográfica sobre los discursos coloniales eurocéntricos que durante el siglo XVIII se construyeron alrededor del cuerpo y los sentidos del indígena americano. Situada en la teoría decolonial, mostraré cómo las ideas europeas sobre el cuerpo y la sensorialidad indígena americana ponen en evidencia lo que el filósofo Nelson Maldonado ha denominado "colonialidad del ser".

PALABRAS CLAVES: cuerpo; sentidos; indígenas; colonialidad del ser; discursos coloniales eurocéntricos.

ABSTRACT: The objective of this article is to present, in a general way, some of the advances in the historiographic compilation of the eurocentric colonial discourses constructed during the eighteenth century around the body and senses of american indigenous peoples. Situated in decolonial theory, I will demonstrate how european ideas surrounding the body and senses of american indigenous peoples reveal what the philosopher Nelson Maldonado called "coloniality of being".

KEYWORDS: body; senses; indigenous peoples; coloniality of being; eurocentric colonial discourses.

\section{Introducción}

El teólogo jesuita y cronista español José de Acosta, en su libro De procuranda Indorum Salute, caracteriza a los "mexicanos y peruanos" como pueblos de segunda clase, por tener "imperios, sistemas de gobierno, leyes e instituciones [que] todo el mundo puede en justicia admirar" (ACOSTA, [1 588] 1984, p. 61). Éstos, inclusive:

\footnotetext{
${ }^{1}$ Doctoranda en Historia del Arte indígena en América. Facultad de Filosofía y Letras. Posgrado en Historia del Arte, Universidad Nacional Autónoma de México. E-mail: maytevenusmayo@gmail.com .
} 
[...] suplieron (parece casi increíble) la escritura con tal derroche de ingenio que guardan memoria de su historia, ritos y leyes y, lo que es más, de la trayectoria de los tiempos y del recuento de los números con unos signos y memoriales por ellos inventados [...]. No obstante están todavía muy lejos de la recta razón y de las prácticas propias del género humano (ACOSTA, [1588] 1984, p. 61).

Y sin que esta "clase de pueblos" fuera suficiente para caracterizar aquello que no es propio del género humano, añade:

\begin{abstract}
Viniendo ya la tercera y última clase de bárbaros, es imposible decir el número de pueblos y regiones del este Nuevo Mundo que comprende. En ella entran los hombres salvajes, semejantes a las bestias, que apenas tienen sentimientos humanos. Sin ley, sin rey, sin pactos, sin magistrados ni régimen de gobierno fijos, cambiando de domicilio de tiempo en tiempo y aun cuando lo tienen fijo, más se parece a una cueva de fieras 0 a establos de animales [...]. Pertenecen también a esta clase aquellos bárbaros que, aun sin ser tan fieros como tigres o panteras, poco se diferencian, sin embargo, de los animales, también ellos desnudos, asustadizos y entregados a los más degradantes vicios de Venus o incluso de Adonis. Tales dicen ser los que los nuestros llaman moscas en el Nuevo Reino [de Granada] [...]. A todos estos hombres o mediohombres es preciso darles instrucción humana, para que aprendan a ser hombres [...] (ACOSTA, [1588] 1984, p. 69-70).
\end{abstract}

Fragmentos similares a éstos, difundidos desde el siglo XVI hasta mediados del siglo XX como una "Historia de América" en sentido estricto, por apoyarse en fuentes escritas, constituyen el cúmulo de rasgos que el concepto de cuerpo indígena va adquiriendo conforme avanza el "desarrollo del espíritu humano" como metáfora occidental del tiempo. Ejemplos innumerables acerca del desdén europeo hacia el indígena, a sus creencias, a su conocimiento, a sus actitudes sensibles, a su ser. En la "Historia del Nuevo Mundo", símiles de animales sobran para referirse a unos "mediohombres" torpes de entendimiento y costumbres inhumanas cuya sola existencia fue acicate de la vasta producción intelectual falocéntrica europea en torno a la "Conquista" de 
las Indias.

La profundidad histórica que encierra este período de tiempo encarna una constante que pone en evidencia cómo desde el siglo XVI hasta mediados del siglo XX, la práctica colonizadora de juzgar al indígena, oscila entre el juicio hegemónico de los primeros siglos de la Colonia de ver al indígena como una criatura irracional de dudosa humanidad e idólatra, que se debe convertir a la perfecta verdad del cristianismo (BESTARD, 1987), o como un espécimen exótico de capacidades sensoriales superiores, un tanto distinto al simio, o un objeto de estudio antropológico creado a partir de las ideas racistas que el humanismo incorporó de la teoría del Origen de las especies de Charles Darwin, en un esquema tan conveniente para Occidente como las etapas de la evolución del hombre.

En este artículo sólo mostraré los discursos con los que se forja durante el siglo XVIII la idea romántica del "salvaje" en absoluta armonía con la naturaleza, cuya agudeza sensitiva cautivará el interés de científicos, humanistas y viajeros que reinventarán la naturaleza sensual del aborigen. Las fuentes de este período conjugan los imaginarios coloniales y las ideas modernas construidas sobre la base del estudio científico, y sirven para mostrar que, aun cuando occidentalmente las épocas colonial y moderna se hayan entendido como realidades históricas distintas que se suceden en el tiempo, la sensorialidad del cuerpo indígena ha sido exaltada, desde la invasión europea hasta mediados del siglo $X X$, como una cualidad instintiva que pone en cuestión su condición humana y racional, lo asemeja a los animales, lo exotiza, lo inferioriza, lo fetichiza y lo define, diferenciándolo cada vez con mayores elementos científicos, del hombre occidental. Esta violencia simbólica de negación y a su vez, praxis exotista de exacerbación del cuerpo, se debe a que en América Latina "modernidad y colonialidad no son fenómenos sucesivos en el tiempo, sino simultáneos en el espacio" (CASTRO-GÓMEZ, 2005, p. 18)². Esta transposición todavía vigente, nos sitúa en un lugar diametralmente opuesto a los efectos de los discursos hegemónicos sobre el cuerpo que imperaron durante la Ilustración

\footnotetext{
${ }^{2}$ Esta propuesta epistemológica tiene su origen en los postulados críticos de los teóricos latinoamericanos Aníbal Quijano, Enrique Dussel y Walter Mignolo (2007), Enrique Dussel (2008), Aníbal Quijano (2000).
} 
europea. Pues aunque algunos teóricos como Michel Foucault, Georges Duby, Alain Corbin, entre otros, hayan difundido la idea de la objetivación, disciplinamiento y biopolítica del cuerpo y los sentidos, como fue el cometido del lluminismo europeo en su praxis positivista y universalizante, en América la historia fue otra. El cuerpo del indígena se pensaba imbuido en la vida práctica para la que los sentidos constituían la única herramienta necesaria, y sumergido en el nivel más bajo de los estados ontológicos del ser. Esta negación no sólo estuvo inspirada en sus inicios por los argumentos aplicados en el siglo XVI para justificar la guerra justa (GINÉS DE SEPÚLVEDA, 1941; BARONA, 1993) contra el indígena del Nuevo Mundo. Los discursos ulteriores alrededor de su cuerpo estuvieron marcados por la supremacía del alma y la razón sobre el cuerpo que René Descartes planteó a través de su frase paradigmática para el Occidente moderno: "Pienso, luego existo", y que concedió a Europa el derecho natural de esclavizar, torturar, quemar, violar, desaparecer, explotar, vender, y demás actos violentos sobre los cuerpos del Nuevo Mundo. Luego, por el aparente juicio benevolente que a finales del siglo XVIII y durante el XIX enalteció al "salvaje", deviene una suerte de mirada europea reconciliada hacia unos cuerpos casi humanos integrados al paisaje natural. El siglo XVIII es pues de lo que trata este texto. Una época ambivalente en los discursos eurocéntricos acerca del Otro-indígena. Se odia su cuerpo y todos los elementos constitutivos de su ser, razón por la cual se niega su condición de humanidad. $Y$ al mismo tiempo, se lo fetichiza y se exacerba su sensorialidad, ejerciendo una praxis de poder colonial sobre los sujetos y sus subjetividades.

Para entender este doble valor concedido al indígena, y por extensión a su cuerpo, en la primera parte de este texto referiré la conceptualización que Nelson Maldonado hace de la "colonialidad³ del

\footnotetext{
${ }^{3}$ Es preciso diferenciar "colonialidad" de "colonialismo". Según nuestro filósofo, "Colonialismo denota una relación política y económica, en la cual la soberanía de un pueblo reside en el poder de otro pueblo o nación, lo que constituye a tal nación en un imperio. Distinto de esta idea, la colonialidad se refiere a un patrón de poder que emergió como resultado del colonialismo moderno, pero que en vez de estar limitado a una relación formal de poder entre dos pueblos o naciones, más bien se refiere a la forma como el trabajo, el conocimiento, la autoridad y las relaciones intersubjetivas se articulan entre sí, a través del mercado capitalista mundial y de la idea de raza (MALDONADO, 2007, p. 131). Un panorama extenso del concepto de colonialidad se encuentra en la producción intelectual de la teoría decolonial, cuyos autores más representativos son: Quijano (2001), Dussel (2008), Sousa Santos (2009) y Mignolo (2007 y 2009).
} 
ser", término acuñado por el autor en el marco de la teoría decolonial, acerca de la cual me limitaré a caracterizar de un modo general. En la segunda parte expongo de manera sucinta las primeras formas de historia universalizante que ponderan la idea del cuerpo indígena como medio de subsistencia y única propiedad, características inherentes a un estado incipiente de complejidad en la escala de desarrollo civilizatorio. $Y$ en la tercera, simultánea cronológicamente a la anterior, hago referencia a la idealización de la vida "al natural" de los "salvajes" como ejemplo de sociedad igualitaria libre de las prisiones que la civilización imponía al hombre europeo. Esta tendencia rousseausiana, nutrida por la literatura de viajes y la etnología de "poltrona" en apariencia, opuesta a los discursos mecanicistas sobre el cuerpo del indígena, seguirán teniendo el mismo fondo ontológico, la manifestación de la naturaleza en el cuerpo sexualizado y feminizado del hombre indígena, y la ausencia total, por esta condición, de capacidad intelectiva.

\section{Sobre la "colonialidad del ser" indígena americano}

Como es sabido, una de los debates más férreos en el medio teológico durante el siglo XVI giró en torno a la pregunta sobre si los "indios" americanos tenían alma o no. Este debate surgido de la asimilación europea de la inferioridad del indígena como una verdad, el 2 de junio de 1537 queda resuelto a través de la bula papal Sublimis Deus emitida por el Papa Paulo III. Este documento promulgará que:

[...] prestando atención a los mismos indios que como verdaderos hombres que son, no sólo son capaces de recibir la fe cristiana, sino que según se nos ha informado corren con prontitud hacia la misma; y queriendo proveer sobre esto con remedios oportunos, haciendo uso de la Autoridad apostólica, determinamos y declaramos por las presentes letras que dichos Indios, y todas las gentes que en el futuro llegasen al conocimiento de los cristianos, aunque vivan fuera de la fe cristiana, pueden usar, poseer y gozar libre y lícitamente de su libertad y del dominio de sus propiedades, que no deben ser reducidos a servidumbre y que todo lo que se hubiese hecho de otro modo es nulo y sin valor, [asimismo declaramos] 
que dichos indios y demás gentes deben ser invitados a abrazar la fe de Cristo a través de la predicación de la Palabra de Dios y con el ejemplo de una vida buena, no obstando nada en contrario ${ }^{4}$.

Sin embargo, tal declaración no tuvo ningún efecto en la práctica. La racialización se había incrustado en el imaginario y en la cotidianidad marcada por las relaciones verticales propias de la colonialidad. Se da así la "heterogeniedad colonial", definida por Maldonado como las múltiples formas de sub-alterización asociadas a la noción de raza, formas que alcanzan su fin último en la deshumanización del indígena y el negro (MALDONADO, 2007, p. 133).

La categoría de bárbaro conferida al indígena estaba anclada al grado más bajo de lo humano y por lo tanto, aunque la Iglesia hubiera proclamado su humanidad, ontológicamente esta condición permaneció en duda. La duda en el pensamiento cartesiano occidental constituye el medio por el cual se llega a la certidumbre. "El rol del escepticismo es central para la modernidad europea" dirá Maldonado, agregando que el "escepticismo sobre la humanidad de los sub-otros colonizados y racializados" (MALDONADO, 2007, p. 134) será la particularidad de la actitud imperial en América. El filósofo, basado en dos autores, caracteriza la actitud imperial como un maniqueísmo misantrópico.

Siguiendo la interpretación fanoniana del colonialismo como una realidad maniquea, la relación fundamental de tal maniqueísmo con la misantropía, como indica Lewis Gordon, caracterizaría esta actitud como un maniqueísmo misantrópico racista/imperial, el cual también puede entenderse de forma más simple como actitud imperial.

[...] el escepticismo maniqueo misantrópico no duda sobre la existencia del mundo o el status normativo de la lógica y la matemática. Éste, más bien, cuestiona la humanidad de los colonizados. La división cartesiana entre res cogitans (cosa pensante) y res extensa (materia), la cual tiene como una de sus expresiones la división entre mente y cuerpo, es precedida por la diferencia colonial antropológica entre el ego conquistador y el ego conquistado (MALDONADO, 2007, p. 134).

Traducción de la bula papal Sublimis Deus. Disponible en http://webs.advance.com.ar/pfernando/DocsIglLA/Paulo3_sublimis.html. Acceso enero 24 de 2016. 
Referirnos aquí al escepticismo maniqueo misantrópico que retoma Maldonado de Frantz Fanon y Lewis Gordon 5 , cobra importancia por cuanto en él quedan consignadas dos premisas. La primera: la humanidad negada al colonizado, y la segunda: la separación entre la mente y el cuerpo, entidades que traducen la relación vertical entre conquistador y conquistado, europeo y no-europeo, blanco y noblanco. Dicotomías siempre presentes en las lógicas de la colonialidad6. "El escepticismo misantrópico (nos dice el autor), expresa dudas sobre lo más obvio." Los cuestionamientos absurdos acerca del indígena consistían en: "¿eres en realidad humano?" "Tienes derechos" se transforma en "ipor qué piensas que tienes derechos?" De la misma manera, expresiones como "eres un ser racional" se convierte en la pregunta "¿eres en realidad racional?" (MALDONADO, 2007, p. 136).

Estas preguntas, de acuerdo con el principio de incertidumbre del pensamiento cartesiano, predominaban sobre las respuestas. El debate sobre si los indios tenían alma o no, se dio al mismo tiempo en que Ginés de Sepúlveda defendía la tesis de que la guerra contra los "infieles" era justa. Cuando se llegó al común acuerdo sobre la justicia de esta causa, los códigos éticos de la guerra se habían transgredido y distorsionado completamente (MALDONADO, 2007, p. 137-138). Jean Pierre Clément sostiene que todas las "crueldades" denunciadas por Bartolomé de las Casas iban en contravía de las reglas con que se concebía legítimamente una guerra en la Europa antigua y medieval. Incluso, las atrocidades cometidas en el Nuevo Mundo superaban las expectativas del más célebre enemigo del indígena, Juan Ginés de Sepúlveda. Clément advierte a este respecto:

Un hombre como Sepúlveda, partidario del enfrentamiento bélico, exige no obstante determinadas condiciones para su iniciación y desarrollo; así precisa en su Democrates primus, que se ha de mostrar rectitud en el modo de ejecución, lo que significa que la acción militar ha de ser la más moderada posible, que hay que evitar los abusos de la soldadesca, y el hacer daño a inocentes (mujeres, niños y ancianos) (CLÉMENT, 1998, n. p.).

\footnotetext{
${ }^{5}$ Cf. Maldonado (2002 y 2005).

${ }^{6}$ Acerca de estas dicotomías también véase en Castro y Grosfoguel (2007).
} 
Aunque en Europa la esclavitud de los vencidos constituía parte de los códigos éticos de la guerra, a partir de la invasión a América y la declaración de la guerra justa contra sus habitantes, la no-ética se naturaliza y se transforma en condena. Esta condena propicia la asimilación de la servidumbre y la esclavitud como consecuencias naturales de la colonización y la conquista. La no-ética se radicaliza incluyendo el genocidio, la feminización y completa sumisión del hombre, y la violación de la mujer (MALDONADO, 2007, p. 137-140).

Ahora bien, el filósofo precursor de la "colonialidad del ser" nos remite a los conceptos de ser, según Descartes y Heidegger. No pretendo profundizar en estas cuestiones filosóficas pero para comprender cómo Maldonado articula y configura su concepto de colonialidad del ser, es preciso hacer un esbozo de ellas. Parte importante de su propuesta se basará en la tesis del filósofo argentino Enrique Dussel, quien plantea el ego conquiro como antecedente constitutivo del ego cogito de René Descartes. Este autor señala que: "ego conquiro [yo conquisto]" (DUSSEL, 1994, p. 40) es la "proto-historia de la constitución del ego cogito [yo pienso]; se ha llegado a un momento decisivo en su constitución como subjetividad, como "voluntad-de-poder" (DUSSEL, 1994, p. 47). Esta "voluntad-de-poder" es la esencia del ego conquiro, con que el hombre europeo se asume Señor de los nuevos "reinos conquistados" y es, por tanto, elemento integral y anterior al ego cogito con que la subjetividad moderna se erige frente a los sujetos racializados de las Américas. Dussel lo afirma así: "del "ego" que, de 1492 a 1636 (momento en el que Descartes expresa definitivamente el ego cogito en el Discurso del Método), recorre el primer momento de la "constitución histórica" de la Modernidad (DUSSEL, 2008, p. 13).

Nelson Maldonado señala que Descartes, cuyas certidumbres alcanzaba supuestamente por medio de la duda metódica, nunca cuestionó cómo el ego conquiro iba a funcionar en la mente del europeo, ya enajenada en la negación de la humanidad de los sujetos colonizados (MALDONADO, 2007, p. 144). Heidegger, en su obra Ser y Tiempo, criticará a Descartes y la filosofía moderna por el anquilosamiento en torno al ego cogito [yo pienso]. Esto en palabras de 
Maldonado:

La máxima cartesiana, Cogito ergo sum, o "pienso, luego soy", introducía, sin embargo, lo que Heidegger consideraba una noción más fundamental que el cogito mismo: el concepto de ser. "PIENSO, luego soy" adquiría sentido, para Heidegger, en tanto significaba a su vez "pienso, luego SOY". La pregunta del ser aparece en la segunda parte de la formulación cartesiana: el SOY. Esta parte de la formulación es la que sirve de fundamento para la interrogación heideggeriana del ser (MALDONADO, 2007, p. 144).

A partir de tal postulado de Heidegger, Maldonado va a encontrar que tanto Descartes como Heidegger olvidaron cuestionar dos dimensiones de capital importancia en sus formulaciones filosóficas. Esto, según nuestro autor, será:

Si el ego cogito fue formulado y adquirió relevancia práctica sobre las bases del ego conquiro, esto quiere decir que "pienso, luego soy" tiene al menos dos dimensiones insospechadas. Debajo del "yo pienso" podríamos leer "otros no piensan", y en el interior de "soy" podemos ubicar la justificación filosófica para la idea de que "otros no son" o están desprovistos de ser. De esta forma descubrimos una complejidad no reconocida de la formulación cartesiana: del "yo pienso, luego soy" somos llevados a la noción más compleja, pero a la vez más precisa, histórica y filosóficamente: "Yo pienso (otros no piensan o no piensan adecuadamente), luego soy (otros no son, están desprovistos de ser, no deben existir o son dispensables) (MALDONADO, 2007, p. 144).

Entonces, cuando recordamos que el acto de pensar para la filosofía y el pensamiento occidental moderno se constituye en la razón por la cual el hombre es, el enunciado ausente en la formulación heideggeriana "Pienso, luego soy", el indígena americano, considerado bárbaro, luego no razona ni piensa, no-es. Esta tesis poderosa que confronta el escepticismo misantrópico y la piedra angular de la filosofía moderna, se extiende al plano ontológico:

El privilegio del conocimiento en la modernidad y la negación de facultades cognitivas en los sujetos racializados ofrecen la base para la negación 
ontológica. En el contexto de un paradigma que privilegia el conocimiento, la descalificación epistémica se convierte en un instrumento privilegiado de la negación ontológica o de la sub-alterización. "Otros no piensan, luego no son". No pensar se convierte en señal de no ser en la modernidad (MALDONADO, 2007, p. 145).

Este no-ser implícito es lo que convierte al indígena y al negro en categorías raciales preferenciales de la colonialidad, seres invisibles, deshumanizados, y por tanto, objetos dispensables (MALDONADO, 2007, p. 150). Estas serán, de acuerdo con las ideas de Maldonado, las expresiones primarias de la colonialidad del ser: "la violación del sentido de la alteridad humana, hasta el punto donde el alter-ego queda transformado en un sub-alter" (MALDONADO, 2007, p. 149). Lo cual permite al colonizador ejercer una praxis naturalizada y ordinaria de control, castigo, esclavitud, racial, genocidio, y no-ética de la guerra (MALDONADO, 2007, p. 148-154).

Según Maldonado el aporte de Descartes al pensamiento moderno serán los dualismos mente/cuerpo y mente/materia, cuya articulación sirve para:

1) convertir la naturaleza y el cuerpo en objetos de conocimiento y control; 2) concebir la búsqueda del conocimiento como una tarea ascética que busca distanciarse de lo subjetivo/corporal; y 3) elevar el escepticismo misantrópico y las evidencias racistas, justificadas por cierto sentido común, al nivel de filosofía primera y de fundamento mismo de las ciencias. Estas tres dimensiones de la modernidad están interrelacionadas y operan a favor de la continua operación de la no -ética de la guerra en el mundo moderno (MALDONADO, 2007, p. 145).

Tales dimensiones, como veremos, se aplicarán, se ejercerán y se naturalizarán de manera ininterrumpida y sistemática sobre los sujetos colonizados/racializados. El cuerpo es, en este sentido, instrumento perfecto de todas las formas de dominación y deshumanización y materia mediante la cual se reproducen durante generaciones enteras, múltiples experiencias de degradación humana. Maldonado al señalar que "La colonialidad es un orden de cosas que coloca a la gente [racializada] bajo la observación asesina y violadora de un ego vigilante" 
(MALDONADO, 2007, p. 138), pondrá en resonancia algunas de las ideas que Michel Foucoult desarrollará mediante el concepto del panóptico. No obstante, cuando se trata de una observación asesina y violadora cuyo "objeto privilegiado de la violación es la mujer" (MALDONADO, 2007, p. 138) a la que se pensaba mucho más inferior que el hombre y que a éste, como veremos con posterioridad, se lo feminizó y se lo redujo a no-sujeto, la vigilancia y el castigo de los cuerpos en las cárceles, psiquiátricos y demás instituciones donde se erige el poder y control sobre los cuerpos occidentales a los cuales nos remite el controversial filósofo francés, quedan muy por encima de la infrahumana experiencia colonial americana. El filósofo argentino Enrique Dussel refiriendo la relación entre el ego conquiro/cogito y el ego fálico del mundo europeo en su lógica opresora, afirma lo siguiente:

La concepción fálica del mundo europeo-medieval viene ahora a sumarse a la sumisión a la que se han visto llevados los indios vencidos. Los 'hombres varones' dice Bartolomé de las Casas- son reducidos, "oprimiéndoseles con la más dura, horrible y áspera servidumbre"; pero esto con los que han quedado vivos, porque muchos han muerto; sin embargo, "comúnmente no dejan en las guerras la vida sino a los mozos y las mujeres". El conquistador, ego fálico armado de caballos, perros, espadas de hierro, mata o domina al varón indio, y se "acuesta" con la india: las indias "quedan amancebadas con los dueños de las casas o estancias u obrajes, o con mestizos o mulatos o negros, gente desalmada" (DUSSEL, 1977, p. 99).

El escepticismo misantrópico nos dice Maldonado coloca a los nosujetos colonizados en una condición de servidumbre y esclavitud donde la sexualización y la racialización son mecanismos permanentes de control, explotación y violación de los cuerpos racializados (MALDONADO, 2007, p. 139-140).

\section{La metáfora naturalista del cuerpo indígena en el siglo XVIII}

Es a partir de Voltaire que el sentido de la historia teológica, que hasta este momento regía la moral de la sociedad europea, se empieza a 
concebir de manera distinta. Al relato histórico medieval, antaño imperante a través de principios dogmáticos impuestos por la religión judeocristiana, Voltaire se le opone radicalmente proponiendo la filosofía de la historia como ciencia del conocimiento universal que postula al hombre como sujeto de la historia, y por tanto como una "ciencia del origen de las costumbres de los pueblos y el desarrollo del espíritu humano" (BESTARD, 1987, p. 221).

Conforme al paradigma racionalista, al reunir ciertos elementos de "verdad científica" como hechos constatables mediante analogías y diferencias entre los pueblos del Viejo y Nuevo continente, Voltaire persuade a los historiadores de su época a dejar atrás el origen metafísico del hombre y analizar, más bien, las influencias que ejerce el medio en la población. Como mostraré más adelante, la estimación del clima fue un factor determinante para la conformación del temperamento humano, que ya se había advertido desde el siglo XVI y que también será objeto de interés del barón de Montesquieu, otro de los célebres pensadores de la Ilustración. Por eso, a partir de este momento la historia sólo girará en torno al espíritu humano que es, según Voltaire, de carácter universal. Sin embargo, tal unidad sólo tendrá coherencia en relación a los sujetos con historia, pues son ellos quienes labran el camino unidireccional del progreso. A este respecto Joan Bestard señala:

En Voltaire hay dos tiempos históricos que se anulan mutuamente y permiten inaugurar el proyecto de una historia universal del espíritu humano. Uno es el propio de los pueblos que, sin historia, sin escritura, con usos y costumbres, fábulas y tradiciones, y en el límite de la "razón empezada" están inmersos en la misma "estupidez" y en un círculo de repeticiones de las mismas costumbres. Otro es propio de los pueblos con historia, leyes e instituciones y registros escritos, que han roto el círculo de las repeticiones parar entrar en la línea del progreso acumulativo (BESTARD, 1987, p. 223).

En efecto. Aunque son dos tiempos históricos, según los conceptos de su historia universal, Voltaire anula el que presiden los pueblos "sin historia", y otras características evidentemente idénticas a las que desde el siglo XVI se habían atribuido al indígena americano. 
Colonizado/racializado, eximido de una sobriedad calculada llamada humanidad, el indígena es para el escritor más influyente del iluminismo europeo, alguien inmerso en la estupidez cuyos usos y costumbres de infinita repetición lo ponen en el límite de la "razón empezada". Estar sumidos en un estadio primario de la especie humana, para Voltaire significa que la civilización de la que es representante estuvo "hundida durante una larga serie de siglos en [un] estado tan parecido al de los brutos, e incluso inferior en muchos aspectos [...]" (VOLTAIRE, 1959, p. 170). Haber superado este estadio, según él, es gracias a unas "circunstancias favorables" que hicieron posible "que el hombre se elevara por encima de la vida animal" (VOLTAIRE, 1959, p. 170). Vivir en chozas, vestirse con pieles de animales que cazan y andar casi desnudos, son algunos de los usos corporales de estos seres en estado de "pura naturaleza", cuyo apremio por suplir las necesidades más básicas no les ha permitido desear ir hacia lo desconocido (BESTARD, 1987, p. 223). Este primer "estado de ignorancia y rudeza [es el que según Voltaire] se denomina estado de pura naturaleza" (VOLTAIRE, 1959, p. 170).

En este mismo sentido, Adam Smith, a partir de sus reflexiones en torno a la división del trabajo y convencido de la superioridad alcanzada en la escala de desarrollo humano por cuenta de la industrialización y el capitalismo emergentes en los países europeos dueños de colonias, persuadirá de forma poco creativa a su público europeo sobre la inferioridad y el salvajismo en el que todavía se encuentran las "tribus de América". Nótese que toda la caracterización que sigue, concerniente a la primera de las cuatro etapas de desarrollo económico, expuesta en su libro La Riqueza de las naciones (1776), implícitamente repite al nivel de las palabras el mismo juicio emitido por los españoles durante los dos siglos antecedentes acerca del "indio salvaje" de América. Sólo que ahora añade a su descripción la falta de territorios capitalizables, y la noción capitalista del trabajo:

El estadio más bajo y más salvaje es el que encontramos en las tribus de América. Están compuestas por sus recolectores, pescadores y cazadores. Lo que los caracteriza es la caza. Sus territorios son poco extensos. Tienen un alto grado de libertad. No existe la idea de propiedad. No hay 
acumulación ni disputas. [...] Su única tarea cazar esos animales o capturar los peces. Recolectar fruta difícilmente puede considerarse trabajo. La única actividad que entre ellos merece el nombre de trabajo es la caza. Ésta es la edad de los cazadores (SMITH, $\mathrm{LJ}(\mathrm{A})$, I, p. 27).

Carentes de elementos indicadores de lo que Smith preconizaba como una sociedad próspera, e imbuidos en actividades de subsistencia que si acaso merecían estimarse como trabajo, los salvajes en la mentalidad europea serán la antítesis perfecta del deber ser de una nación, pueblo y sujeto dignos de admiración. El padre jesuita José Lafitau, en quien Smith basó sus conocimientos sobre la gente americana, afirmará que los salvajes "Frente a los europeos, han mantenido una "moderación que les ha enseñado a contentarse en poco", tienen una "pereza natural que los hace tan indolentes, que prefieren privarse de las mismas ventajas que nos envidian, antes que hacer esfuerzos para procurárselas" (LAFITAU apud BESTARD, 1987, p. 173). Tales esfuerzos de acuerdo con el liberalismo económico de Smith deberán estar encausados a la acumulación del capital y la lucha por la libertad y la propiedad. La falta de esto último es uno de los tópicos que más escandaliza del salvaje a los ilustrados. Por eso se dirá que "Entre los salvajes la propiedad empieza y acaba con la posesión, y parece raro que tengan alguna idea de algo suyo como propio, a no ser su propio cuerpo" (BESTARD, 1987, p. 214).

Es interesante ver cómo a la luz de las ideas del cuerpo como única propiedad del indígena se va instaurando también su cuerpo como medio de subsistencia. La historia se contará mediante distinciones jerárquicas, ya sabemos por quién están encabezadas, establecidas de acuerdo a la mayor o menor complejidad de los modos de subsistencia y la organización social. Luego, el cuerpo indígena es el medio de subsistencia y propiedad del sujeto que implica la menor complejidad de la escala de desarrollo civilizatorio.

La reafirmación de estas diferencias, ya existentes y naturalizadas poco a poco en la mentalidad europea, comienza a erigirse como una bandera más del colonialismo a partir de las expediciones científicas y los viajes de aventureros que, habiendo tenido la experiencia de conocer en persona las formas de gobierno, usos y costumbres de tierras 
inhóspitas habitadas por salvajes, gozarán de la credibilidad de los historiadores y naturalistas empeñados en reconstruir el origen universal de la naturaleza humana.

James Mackintosh afirmará que la historia "Es un amplio museo donde se puede estudiar los diversos especímenes de la naturaleza humana" (MACKINTOSH, 2009, p. 27). Y ello será el preludio de la consideración del hombre americano como espécimen de la naturaleza, cuerpo-objeto de control y estudio científico. La idea de museo surge pues en este ambiente enciclopedista de la llustración francesa que tenía por misión reunir la máxima cantidad de pruebas que demostraran que Europa occidental poseía el conocimiento universal de la humanidad. América convertida en museo de Europa será el epítome del estado de pura naturaleza, y sus habitantes, cuerpos que conviven en perfecta armonía con el medio natural así como también, curiosidades de exhibición que ocuparán un lugar privilegiado en los gabinetes dieciochescos.

Pero así mismo, traerá a la memoria histórica aquél pensamiento de Cristóbal Colón, poco antes de su decepción acerca de las Indias: "En el mundo creo que no hay mejor gente ni mejor tierra" (apud TODOROV, 2007 , p. 46). Es en este contexto que el eco rousseauniano cargado de un exotismo romántico que comienza a florecer, resonará en la antropología que "ve en el salvaje, el campesino, el marginal a la sociedad, la constatación de los valores de bondad humana y de armonía cultura/naturaleza" (GONZÁLES, 1987, p. 8).

\section{Falocentrismo y epicureísmo de los cuerpos americanos}

El gabinete de historia natural y el jardín botánico serán pequeñas capturas de la vida espontánea y abundante que prometía América. Los relatos de viajes se convertirán en una ventana a ese Nuevo Mundo lleno de salvajes cuyas formas de vida ennoblecían la libertad y prometían la emancipación del andamiaje pesado y coercitivo de la cultura y la 
civilización europeas. En la famosa y difundida histoire des deux Indes ${ }^{7}$, Raynal afirmará: "[...] Sea como sea, podemos decir que la ignorancia de los salvajes ha iluminado, de alguna manera, a los pueblos civilizados" (RAYNAL apud BESTARD, 1987, p. 256).

Para que ideas como ésta empezaran a conquistar el imaginario europeo, cumplieron un papel protagónico el relato de viajes del barón de Lahontan, Lois-Armand de Lou d'Arce, por los estados de Wisconsin y Minnesota y el río Misisipí. Publicado en 1703 y luego vuelto a publicar doce veces en francés, traducido al inglés, alemán y holandés, entre 1703 y 1741, y al italiano a principios del siglo XIX, inspirará entre otros "Las cartas persas de Montesquieu, el Discurso sobre la desigualdad de Rosseau, el Ensayo sobre las costumbres, el Cándido y el ingenuo de Voltaire, y sobre todo [el] Suplemento al viaje de Bougainville de Diderot" (BESTARD, 1987, p. 257).

Jean-Jaques Rousseau será el representante de un ideario romanticista con el que ahora se mirará a un salvaje deshabitado de los vicios que se le habían imputado desde el siglo XVI. Protagonista insigne de la bondad y la pureza, el salvaje rousseauniano encarna el vivo ejemplo de los valores primos de una sociedad igualitaria. Hace uso estricto de lo que le prodiga la naturaleza, caza y recolecta lo necesario para suplir sus necesidades físicas; no destruye su entorno sino que se conforma con una cueva donde refugiarse; se relaciona con sus congéneres armónicamente; no posee ninguna cosa que le haga enfrentarse competitivamente con su comunidad. Es libre y no medita ni reflexiona. En cambio, al hombre civilizado que ponderaba la razón como una de sus cualidades inherentes se le atribuirá el apelativo de "animal depravado", antaño cualidad exclusiva del salvaje.

Rousseau, sin embargo, no se refiere a los colonizados americanos ni africanos. El pensador suizo creará esta categoría imaginaria haciendo alusión a un ser que ya no existe o que nunca existió y que tal vez, no existirá jamás (BARTRA, 1997, p. 171). Roger Bartra afirma que incluso en su Discurso sobre el origen y los fundamentos de la desigualdad entre los hombres, el filósofo aclara que

\footnotetext{
${ }^{7}$ Fuente original: 1783, VII, p. 163. Aunque el libro se publicó como anónimo se le ha atribuido a Guillaume-Thomas Raynal, pero se ha visto que es el compendio de numerosos escritos de diferentes autores, siendo Diderot uno de los más identificables.
} 
"no osará hablar de esas naciones felices que no conocen siquiera el nombre de los vicios que a nosotros nos cuesta tanto reprimir" (BARTRA, 1997, p. 171). Insistió en esto de manera taxativa seguramente también porque jamás pisó tierras americanas.

Sin embargo, ni él mismo alcanzó a imaginar el efecto que causarían sus Discursos en la consideración del salvaje americano. Acontecerá paulatinamente un cambio de papeles que tendrá origen en el empoderamiento de una burguesía que reclamaba, en contra del racionalismo en decadencia, la legitimidad de sus sentimientos y pasiones. Una célula constitutiva del empirismo ofrecerá al corazón pasional de la época la justificación de la huida y el autoexilio de la civilización racionalista al paraíso terrenal que Diderot configuró sin haber viajado nunca a los confines donde Bougainville inspiró su Suplemento. En uno de los pasajes del relato del Viaje a Tahití de Bouganville, enajenado por la vida feliz, el sentido de libertad y la simplicidad natural que respiraban los lugareños, el viajero cuenta:

Me creía transportado en el jardín del Edén: recorríamos una planicie tapizada de césped, cubierta de hermosos árboles frutales y recortada por riachuelos que mantienen un frescor delicioso, sin ninguno de los inconvenientes que conlleva la humedad. Un pueblo numeroso disfruta de los tesoros que la naturaleza ha volcado a manos llenas sobre él. Nos encontrábamos grupos de hombres y mujeres sentados a la sombra de los vergeles: todos nos saludaban amistosamente; los que nos encontrábamos por los caminos se hacían a un lado para dejarnos pasar; en todo lugar veíamos reinar la hospitalidad, el respeto, una dulce alegría y todas las apariencias de la felicidad (BOUGANVILLE, 1982, p. 37).

Estas escenas grandilocuentes sobre la generosidad prodigada por la naturaleza y sus pares humanos, están acompañadas de las experiencias corporales que se les invitaba a tener:

Cada día nuestras gentes se paseaban por el país sin armas, solos o en pequeños grupos. Se les invitaba a entrar en las casas, en las que se les daba comida; pero en este país la cortesía de los dueños no se limita a una ligera colación; les ofrecían a sus hijas; la choza se llenaba al instante de un gentío curioso, hombres y mujeres, que formaban un círculo alrededor del 
huésped y de la joven víctima del deber hospitalario; se recubría el suelo con hojas y flores, y los músicos cantaban los acordes de la flauta un himno de placer. Venus es aquí la diosa de la hospitalidad; en su culto no se admiten misterios, y cada placer es una fiesta para la nación (DIDEROT, 1982, p. 36-37).

Las historias de tales placeres obtenidos por Bouganville y sus acompañantes franceses mediante el permiso de los tahitianos, fueron definitivas en la conformación de un imaginario sexualizado del cuerpo de la gente "salvaje". Pero a la vez, fueron el preludio de otro argumento de inferiorización del ser no-occidental que Diderot en su Suplemento disfraza de la imagen romántica de un anciano, el cual, indignado por el proceder libidinoso de los visitantes, vocifera para ellos una lección sobre la ausencia de propiedad y los odios a que esto conducen:

[Los tahitianos] seguimos, dice el anciano, el puro instinto de la naturaleza, y tú has intentado borrar de nuestras almas su carácter. Aquí todo es de todos y tú has predicado no sé qué distinción de lo tuyo y lo mío. Nuestras hijas y nuestras mujeres no son comunes; has compartido este privilegio con nosotros y has venido a encender en ellas furores desconocidos. En tus brazos enloquecieron, y tú te volviste feroz entre los suyos. Ellas empezaron a odiarse; vosotros os asesinasteis por ellas; y ellas han vuelto a nosotros teñidas con vuestra sangre (DIDEROT, 1982, p. 109-110).

Utilizando conveniente y hábilmente la voz del anciano tahitiano, el filósofo hace una contrastación de formas civilizadas y usos instintivos de la naturaleza corporal en la que queda implícita la conquista de los cuerpos de las mujeres por una aparente superioridad sexual de los viajeros que ha desencadenado el desenfreno y el odio entre ellas. La potencia sexual de los tahitianos queda así doblegada. Diderot hablando a través del anciano, describe las bajezas a las que son capaces de llegar sus propios coterráneos, figuras del mundo civilizado, y pone al desnudo las atrocidades que finalmente cometerán de múltiples formas en contra de las colonias europeas:

Llorad, pues, desgraciados tahitianos, llorad, pero que sea por la llegada y no por la partida de estos hombres ambiciosos y falaces. Llegará día que los conozcáis mejor. Llegará día en que, con el trozo de madera que 
veis atado en la cintura de éste en una mano y con el hierro que cuelga de aquél en otra mano, vendrán para encadenaros, degollaros y someteros a sus extravagancias y a sus vicios. Llegará día en que estaréis a su servicio, tan corrompidos, tan viles y tan desgraciados como ellos. Pero yo tengo un consuelo: he llegado al final de mi carrera y la calamidad que os anuncio ya no la veré (BOUGANVILLE, 1982, p. 109).

Diderot será así iniciador de un "primitivismo hedonista" como le Ilama Bestard, a partir del cual se critica la asociación moral del acto sexual a sentimientos como la vergüenza, los celos y la castidad (BESTARD, 1987, p. 250). Sin embargo, en esta postura literaria le resultará difícil esconder esa ambivalencia de fetichización y negación siempre presente en las relaciones sobre el cuerpo no-occidental. Así lo refiere Antonio Gonzáles:

Diderot concluye en un epicureísmo acomodaticio, aceptando la doble faz del sacerdote de su Suplemento, que hace el amor a las tahitianas para «no contrariar la costumbre», mientras se repite «ipero mi religión, pero mi estado!». Es el desdoblamiento del comediante burgués, del colonizador- explorador dieciochesco, en una singular relación de atracción-repulsión sobre lo primitivo [...] (GONZÁLES, 1987, p. 7).

Aquí se pondrá de manifiesto la gran contradicción de los discursos de la época. Joan Bestard citando al ya mencionado Raynal señala:

No, no es verdad que los hombres ocupados en las pesadas artes de la sociedad vivan tanto como el hombre que goza de los frutos de su sudor. El trabajo moderado fortifica, el trabajo excesivo agobia. Un campesino es un viejo a los sesenta años, mientras que los ciudadanos de nuestras ciudades que viven en la opulencia con alguna sabiduría, llegan y pasan a menudo los ochenta años. Las mismas gentes de letras, cuyas ocupaciones son poco favorables a la salud, cuentan entre ellos un gran número de octogenarios. Váyanse lejos de los libros modernos estos crueles sofismas con que se mece a los ricos y a los grandes que se duermen sobre los trabajos del pobre, cierran sus entrañas a sus gemidos, y desvían su sensibilidad de vasallos para apoyarla completamente en sus perros y caballos (RAYNAL apud BESTARD, 1987, p. 274-275). 
Mientras se elogiaba las costumbres y la moral del salvaje como una forma de condenar las superficialidades y perversidades de la vida civilizada, el europeo en su cómodo estado civilizado jamás envidiaría la condición des-humanizada conferida por sus congéneres al hombre salvaje. Aquí cobra importancia el hecho de que ninguno de los filósofos precursores de la noción romántica del noble salvaje haya conocido siquiera alguno de los lugares de los que escribía y que audazmente describía como paraísos terrenales. Bestard reflexiona sobre esta contradicción:

\begin{abstract}
Desde la perspectiva de la historia de los ilustrados, la imagen del salvaje situado en los inicios era la de simplicidad y fragilidad, pero de ninguna manera una forma de vida claramente apetecible para los civilizados. Se podía hablar de una serie de virtudes de los salvajes como de su devoción a la libertad, la igualdad y la independencia, su heroísmo y bravura en la guerra, su sentido de lealtad a su tribu. Pero al mismo tiempo se podían subrayar su debilidad social, su incapacidad intelectual y su mera supervivencia en un medio hostil (BESTARD, 1987, p. 275).
\end{abstract}

Como se sabe, algunos cronistas coloniales ${ }^{8}$ y varios humanistas ilustrados ${ }^{9}$ habían concedido suma importancia a la influencia que ejercía la situación geográfica y el clima en la conformación de los caracteres de las sociedades. El historiador escocés William Robertson, no obstante, en su Historia de América critica la sobredimensión que los filósofos habían otorgado a tal aspecto, haciendo mención de las causas morales y políticas que confluyen en la constitución del ser (ROBERTSON, 1827, II, p. 51-52).

Es relevante subrayar que Robertson, sin haber estado nunca en nuestro continente, hablará sobre la "debilidad del cuerpo y la frialdad del alma" de los americanos recogiendo de la literatura de viajes a otras latitudes, uno de los elementos claves en la praxis de poder colonial sobre el ser: La supuesta superioridad sexual de la que gozaban los viajeros europeos con relación a los nativos. En un comentario decididamente falocéntrico, Robertson esgrime una sentencia que

\footnotetext{
${ }^{8}$ Bartolomé de las Casas, José de Acosta y Pedro Cieza de León, son algunos de éstos.

${ }^{9}$ Voltaire y el Barón de Mostesquieu.
} 
seguramente iluminó en la posteridad las tan acreditadas ideas eurocéntricas de Hegel:

Hemos considerado hasta el presente los pueblos de América únicamente según sus facultades físicas, que estando esencialmente viciadas, habían ocasionado la pérdida de sus facultades morales: la degeneración había alcanzado sus sentidos y sus órganos: su alma se había perdido en proporción a su cuerpo. La naturaleza, que lo había quitado todo a un hemisferio de este globo para darlo al otro, no había puesto en América más que niños, de los que todavía no ha podido hacer hombres [...] (ROBERTSON, 1827, II, p. 153).

Al encontrar en los documentos de viajes que "[entre] las más salvajes naciones americanas existe una antigua costumbre de pasar el primer año después de contraer matrimonio sin consumarlo" (ROBERTSON, 1827, II, p. 564), el autor deducirá que la falta de interés en el acto sexual es signo de la debilidad del deseo en el salvaje, opuesto a la pasión desenfrenada que mostraría el civilizado en una situación similar (BESTARD, 1987, p. 230). Por su parte, el famoso enciclopedista francés Georges Leclerc, conocido como Conde Buffon, acreditará su juicio sobre la debilidad y la pequeñez de los genitales del salvaje en su difundida obra Histoire naturelle, concluyendo que:

No hay que buscar muy lejos la causa de la vida dispersa de los salvajes y su alejamiento para formar sociedad: la más preciosa chispa de fuego de la naturaleza les ha sido negada; les falta ardor hacia la hembra $y$, en consecuencia, el amor hacia sus semejantes (BUFFON, 1791, XI, p. 371).

Siendo Buffon un científico ateo, no dejará saber por quién fue negada aquella chispa de fuego a los salvajes y concediéndosela, por el contrario, a su propia raza. Su convencimiento en cuanto tal le da elementos para quitarle a la invención del "hombre salvaje" las funciones vitales a su cuerpo y el vigor de un alma sin ninguna actividad:

El salvaje tiene pequeños y débiles los órganos de la generación; no tiene pelo ni barba ni ningún ardor por la hembra, aunque más ligero que el europeo, porque está habituado a correr, es mucho más débil de cuerpo; es también mucho menos sensible, y sin embargo más 
María Teresa Guerrero Bucheli - La "Colonialidad del Ser" en los discursos...

tímido y más cobarde; no tiene ninguna viveza, ninguna actividad en el alma; la del cuerpo es menos un ejercicio, un movimiento voluntario, que una necesidad de acción causada por la obligación, quitadle el hambre y la sed, y le destruiréis al mismo tiempo el principio activo de todos los movimientos; se mantendrá estúpidamente en reposo sobre sus piernas o acostado días enteros (BUFFON, 1791, XI, p. 370).

Estas observaciones hechas por Buffon serán pruebas suficientes para demostrar la equivocación de pretender que el desnudo e insensible hombre americano era el principio de la humanidad:

Admirados de la apariencia de degeneración de la especie humana en la extensión del Nuevo Mundo, y asombrados de ver un basto continente ocupado por una raza de hombres desnudos, débiles e ignorantes, sostuvieron algunos autores célebres [...] que todo tenía allí apariencia de un origen reciente; y que sus habitantes llamados hace poco a la existencia y principiando aún su carrera, no podían ser comparados a los de la tierra más antigua y ya perfeccionada (BUFFON, 1791, II, libro IV, p. 44).

Estamos pues, ante la consolidación de un imaginario europeo acerca del indígena americano que redunda en la idea racializada de su cuerpo, ampliamente difundida por filósofos humanistas, historiadores y hasta militares, como el inglés Thomas Gage, cuya comandancia del ejército británico en Estados Unidos le otorga la autoridad para afirmar, basado en un "doctor físico", lo siguiente:

El clima de aquellas partes tiene ese efecto, que produce buena apariencia pero poco sustancia, no sólo en la carne que comíamos sino en todas las frutas del país, las cuales son muy agradables y hermosas de ver, y dulces y suculentas al paladar, pero tienen poca virtud interna o alimento, ni la mitad que una camuesa española o una manzana inglesa de Kent. $Y$ así como las carnes y las frutas son engañosas en su apariencia exterior, lo mismo ocurre con las personas nacidas y criadas allá, que por fuera muestran un bello aspecto y por dentro son falsas y vacías (GAGE, 2001, p. 40).

Esta asociación entre la poca sustancia de los frutos que se dan en este continente con la apariencia engañosa de la gente nativa, estaba 
relacionada con la degeneración de la especie que ocasionaba la posición del territorio en este lugar del globo. Tal degeneración constituía un impedimento para el progreso.

Por su parte Cornelius de Pauw insistirá en que, en el cuadro de la evolución de lo humano, los indios son niños sin una virilidad desarrollada y esta impotencia había sido causada por efecto del clima, degenerando sus órganos y por tanto, su sexualidad (PAUW, 1769). En 1768, repitiendo tal vez al conde Buffon, o quizá, haciendo uso de la idea ya generalizada sobre la ausente chispa de fuego en el indígena americano, afirmará:

La poca inclinación y calor de los americanos por el sexo demostraba indudablemente el defecto de su virilidad y el fallecimiento de sus órganos destinados a la generación: el amor ejercía apenas sobre ellos la mitad de su potencia; no conocían ni los tormentos ni las dulzuras de esta pasión, porque la más ardiente y la más preciosa chispa de fuego de la naturaleza se extinguía en su alma tibia y flemática (PAUW, 1769, I, p. 70).

Lo siguiente probablemente animará a Denis Diderot para que en su Suplemento hiciera el comentario literario arriba citado, referenciando algo casi idéntico a esta frase de Cornelius: "Todas las relaciones están de acuerdo en que las indias estuvieron extraordinariamente encantadas a la llegada de los europeos, cuya lubricidad les hacía parecer sátiros comparados con los naturales" (PAUW, 1769, I, p. 70). En este falocentrismo europeo la "delicadeza" y el "refinamiento" del indígena por no acercarse a la mujer después del "matrimonio" o no violarla en cautiverio, será una aberración, una actitud entendida como afeminamiento, indecencia y debilidad para el amor. El desenfreno sexual y naturalización de la violación a la mujer en circunstancias adversas a ella o de vulnerabilidad se traducirán por parte de los ilustrados occidentales en actos permitidos de "abierta convivencia de los sexos, que está permitida sin culpa en los demás países" (SMITH, 1996, V, p. 9), según A. Smith. El ensayista francés y traductor de célebres libros de viajes, Jean-Nicolás Démeunier, asumiéndose por esta causa conocedor del temperamento sexual del hombre americano, declarará en su obra de tres volúmenes titulada $E /$ 
Espíritu, usos y costumbres de las diferentes naciones, o de la observación de los viajeros e historiadores:

[...] es preciso recalcar que los americanos estaban débilmente organizados para el amor. No conocían a ninguna mujer durante la guerra: nunca han violado a una europea cautiva, y quizá se ha visto varios pueblos que no se acercan a sus mujeres más que largo tiempo después del matrimonio. Se asegura que las mujeres se creían deshonradas y trataban al marido de grosero si se les acercaba. A veces entra en la cabeza de los salvajes ideas muy púdicas y muy delicadas, y no cabe admirarse de que se hubieran refinado tanto sobre la delicadeza (DÉMEUNIER apud BESTARD, 1987, p. 242).

Para este mismo autor, el afeminamiento del indígena tendrá su correlato inmediato en la manera indiana de vestir. Como traductor de la obra de James Cook, el explorador y cartógrafo inglés que recorrió casi todo el mundo, se siente con la autoridad para interpretar que para el hombre americano dotar de brillo y adorno su atavío será la actividad de su mayor atención en busca de su distinción como guerrero, y que contrario a esto, "el vestido de las mujeres [es] muy simple y variado" (apud BESTARD, 1987, p. 243). Este aspecto estético del atuendo se soportaba seguramente en el siguiente argumento de Démeunier:

Para juzgar la condición de las mujeres en cada país, es preciso examinar en qué punto se encuentra la civilización de este lugar. Desde el grado en que vivieron los naturales de América en el descubrimiento del Nuevo Mundo hasta donde han llegado las naciones más civilizadas, hay una infinidad de gradaciones intermedias que influyen de forma distinta en su suerte y en el aprecio en que se las tiene. Los pueblos las respetan más o menos según se alejen más o menos de la vida salvaje [...] (apud BESTARD, 1987, p. 245).

Otro de los argumentos con los cuales se sostenía la idea de la debilidad corporal y la ausencia de libidinosidad en el indígena era la creencia de que el salvaje posee un sentido del olfato mucho más desarrollado que el hombre civilizado. Alain Corbin comenta que entre los pensadores ilustrados y personajes influyentes como:

El padre du Tertre, el padre Lafitau, Humboldt, Cook y los primeros antropólogos están de acuerdo sobre este 
punto. Y si ciertas anécdotas que se difunden a este respecto parecen excesivas, la observación de los niños salvajes no confirma menos la superioridad olfativa del ser que ha crecido fuera de un medio social (CORBIN, 1987, p. 13).

Curiosamente, la médica corporal de Occidente mostrará una cierta inclinación hacia la preservación de los olores fuertes en los individuos, pues esto es signo de vigor y fuerza, de potencialidad sexual y racial. Corbin señala a este respecto que "La intensidad de los efluvios es señal de intensa animalización, atestigua el vigor del individuo y de la raza" (CORBIN, 1987, p. 47). Pero además que, Louis Peisse, un aficionado a la historia y la filosofía médica de la época aseveraba que "Entre las razas o en los individuos débiles, este olor es menos marcado; es más fuerte en las especies muy animalizadas y en los cuerpos muy vigorosos" (CORBIN, 1987, p. 47). Esta observación la hará Corbin en torno a las observaciones empíricas que los médicos hacían, divulgadas a través de las medidas higiénicas con que se exhortaba al sector popular a poner en práctica. Una serie de características sensitivas en un individuo se insinuarán entonces como pertenecientes a un vulgo próximo al salvajismo:

Olisquear, husmear, dar pruebas de agudeza olfativa, preferir los densos olores animales, reconocer el papel erótico de los olores del sexo, engendra sospecha; tales maneras de conducirse, emparentadas a las del salvaje, atestiguan proximidad a la bestia, carencia de refinamiento, ignorancia del código de los usos; en resumen el fiasco de los aprendizajes que definen el estado social. El olfato figura en lo más bajo de la jerarquía de los sentidos [...] (CORBIN, 1987, p. 13).

En efecto. Aquí encontraremos esas contradicciones sutiles contenidas en los discursos coloniales, tan convenientes para mantener la superioridad ontológica europea. Pues, aunque a lo largo de los siglos anteriores se había creado y consolidado un imaginario del salvaje como un ser semejante a las bestias, cuyas costumbres bárbaras y naturaleza animalizada dejaban implícita una impronta odorífera que correspondía con sus símiles, ahora, las especies animalizadas serán los europeos pues sus fuertes emanaciones corporales son una muestra inequívoca de su vigor y su potencia sexual. Con total convicción se cree que: 
Las ablusiones demasiado frecuentes, y con mayor razón los baños, debilitan la animalización y por ende el deseo sexual. Bordeu conoció a individuos vigorosos "odoríferos" destruidos por la higiene y la desodorización. "La piel se había limpiado, las emanaciones y la transpiración fuertes se habían destruido, pero todo lo que caracteriza el sexo se había apagado." Además, el aura seminalis, la fuerza de seducción, "se conserva mejor en los individuos mal cuidados y que no pierden su tiempo y su savia a fuerza de limpiarse" (CORBIN, 1987, p. 47).

Es muy posible que este tipo de creencias se hayan anquilosado en la mentalidad europea del siglo de las luces, luego de considerar desde variadas perspectivas la debilidad del cuerpo indígena a partir de algunos comentarios de los siglos XVI y XVII emitidos por cronistas que notaron con sorpresa la costumbre de la gente americana de bañarse con bastante frecuencia. Josué Sánchez contempla este tópico afirmando que:

Y es precisamente esa costumbre americana de querer bañarse constantemente en su esfuerzo por oler bien lo que asombraba a algunos europeos que siempre buscaron registrar ciertas características de los indoamericanos en un afán por diferenciarse de ellos con el objetivo de proyectarse como superiores ante los americanos. Una diferencia que vieron en los indoamericanos era que se limpiaban "demasiado" (SÁNCHEZ, 1984, n.p.).

El autor citando a varios cronistas de Indias encuentra que además del baño corporal, entre la gente indígena había una gran preocupación por tener las manos y la boca limpias después de comer, lo cual era visto como una "costumbre tan original" (SÁNCHEZ, 1984). Esto también se vio en Brasil, acerca de lo cual, Sánchez encuentra la siguiente observación de Vaz de Caminha:

Vaz de Caminha también notó a unas jóvenes "muy hermosas, con cabellos muy negros, caídos por la espalda abajo [...] y tan limpio tenían el pelo que no nos daba vergüenza mirarlas fijamente" y que "esos hombres parecían muy sanos y limpios" y que por ello eran "como las aves y los animales del monte, que tienen mejores plumas y pelos que los animales 
domésticos (SÁNCHEZ, 1984, n.p.).

En este comentario, además de la rutinaria comparación de los indígenas con animales salvajes, tenemos presente la mirada lasciva con que era observado el cuerpo, especialmente el femenino, cuya desnudez era el acicate del pudor y la vergüenza y al mismo tiempo, de la fijación europea. El autor citando a Jean de Léry señala:

[...] lo que más nos maravillaba de estas brasileñas es el hecho que [...] nunca pudimos conseguir que se vistieran [...] Aún los hombres, de vez en cuando se vestían pero ellas no querían nada... De hecho, para justificar su desnudez, alegaban que no podían prescindir de los baños y que les resultaba complicado tener que desnudarse tan a menudo, que se metían en el agua en la primera fuente o el primer río que encontraban, se mojaban la cabeza y zambullían el cuerpo como cañas, con frecuencia más de doce veces al día. Sus motivos eran razonables, y cualquiera esfuerzo para convencerlas de lo contrario fue totalmente inútil (SÁNCHEZ, 1984, n.p.).

Aun habiéndose conocido esta sana costumbre entre la gente indígena y confirmado que "la higiene personal de los amerindios era superior a la de los franceses, quienes consideraban el baño como inmodesto y no saludable" (Sánchez, 1984), Adolfo Colombres afirma que al haberse hecho efectiva la prohibición mediante ley real de no bañarse, los indígenas "luego eran acusados de sucios" (SÁNCHEZ, 1984 , n.p.).

Lo anterior evidencia en alguna medida la lógica de los discursos eurocéntricos dirigidos contra el cuerpo del nativo americano. Se considera de interés la sensibilidad olfativa del indígena como una capacidad aguda que lo acerca al instinto salvaje y lo reduce en su condición de humanidad, pero cuando se proscriben sus prácticas higiénicas se critica su suciedad corporal. En cambio, los olores fuertes y desagradables en el cuerpo de los europeos los convierten en seres dotados de salud y potencia sexual.

Ya habiendo determinado que la degeneración del cuerpo indígena por causa del clima, los humores de la naturaleza estancada, el baño y la limpieza frecuentes tenían como manifestación la debilidad, la 
pequeñez de los órganos sexuales, la ausencia de virilidad, y por ende, la incapacidad del indígena de regenerar la especie para su transformación en pos del progreso, los discursos falocéntricos de Occidente se combinan en una mezcla indisoluble con aquellos que finalmente refieren la absoluta inexistencia de pensamiento abstracto. En otras palabras, luego de degradar sexualmente el cuerpo indígena, éste se reduce a ser el nivel más inferior de conocimiento del mundo, un vehículo indiferente que si bien puede percibir y sentir ${ }^{10}$ en un modo limitado, nunca podrá contener ni generar ideas abstractas ni generalidades. La sensibilidad existente o no del indígena americano consistirá en un ir y venir de las discusiones cuyo propósito inacabado será confinar a la deshumanización simbólica del cuerpo y, en un sentido general, el ser indígena.

\section{Referencias}

ACOSTA, José de. De procuranda Indorum Salute. Madrid: Consejo Superior de Investigaciones Científicas, 1984.

BARONA, Guido. Legitimidad y sujeción: los paradigmas de la invención de América. Bogotá: Colcultura, 1993.

BESTARD, Joan. Bárbaros, paganos, salvajes y primitivos: una introducción a la Antropología. Barcelona: Barcanova, 1987.

CASTRO-GÓMEZ, Santiago. La Hybris del Punto cero: ciencia, raza e ilustración en la Nueva Granada (1750-1816). Bogotá: Instituto Pensar/Universidad Javeriana, 2005.

CASTRO, Santiago; GROSFOGUEL, Ramón. Prólogo. In: (Org.). El giro decolonial. Bogotá: Instituto Pensar/Siglo del Hombre Editores, 2007. p. 9-24.

CLÉMENT, Jean-Pierre. De las ofensas contra los indios. La injusticia de la guerra y otras violencias, según el Padre Las Casas. In: BATAILLON, Gilles et.al. Las teorías de la guerra justa en el siglo XVI y sus expresiones contemporáneas. México, D.F.: Centro de estudios mexicanos y centroamericanos, 1998.

\footnotetext{
${ }^{10}$ Percibir y sentir durante el siglo XVIII apenas podía considerarse una actividad funcional del cuerpo que no implicaba mayor proceso que el vinculado con lo sensorial. La discusión de estos conceptos por la fenomenología de la percepción y luego, por la antropología de los sentidos tendrá lugar en el siglo XX.
} 
María Teresa Guerrero Bucheli - La "Colonialidad del Ser” en los discursos...

DUSSEL, Enrique. Filosofía ética de la liberación. Buenos Aires: Ediciones Megápolis, 1977. v. 3.

1492 El encubrimiento del otro: hacia el origen del mito de la modernidad. La Paz: Plural Editores, 2008.

GAGE, Thomas. El inglés americano: sus trabajos por mar y tierra o un nuevo reconocimiento de las Indias occidentales. México, D.F.: Libros del Umbral, 2001.

GINÉS DE SEPÚLVEDA, Juan. Tratado sobre las justas causas de la guerra contra los indios. México, D.F.: Fondo de Cultura Económica, 1941.

GONZÁLES, José. El buen salvaje de Rousseau. Inflexión de la Antropología y de la Estética. Gazeta de Antropología, v. 5, n. 3, 1987. Disponible en: http://www.ugr.es/ pwlac/G05_03JoseAntonio_Gonzalez_Alcantud.html. Acceso 20 julio, 2015.

LECLERC, Georges Louis. Historia natural, general y particular. Madrid: Viuda de Ibarra, 1791.

MACKINTOSH, James. A discourse on the study of the law of nature and nations. Londres, 2009.

MALDONADO, Nelson. Post-imperial Reflections on Crisis, Knowledge, and Utopia: Transgresstopic Critical Hermeneutics and the 'Death of European Man'. Review: A Journal of the Fernand Braudel Center for the Study of Economies, Historical Systems, and Civilizations, v. 25, n. 3, 2002.

Decolonization and the New Identitarian Logics after Septem "Eurocentrism and Americanism against the Barbarian Threats. Radical Philosophy Review, v. 8, n. 1,2005

Sobre la colonialidad del ser: contribuciones al desarrollo de un concepto. In: CASTRO-GÓMEZ, Santiago; GROFOGUEL, Ramón (Org.). El giro decolonial: reflexiones para una diversidad epistémica más allá del capitalismo global. Bogotá: Siglo del Hombre Editores, 2007. p. 127-168.

MIGNOLO, Walter. La idea de América Latina. La derecha, la izquierda y la opción decolonial. Crítica y Emancipación, v. 1, n. 2, p. 251-276, 2009.

El pensamiento decolonial: desprendimiento y apertura: un manifiesto. In: CASTRO-GÓMEZ, Santiago; GROFOGUEL, Ramón (Org.). El giro decolonial: reflexiones para una diversidad epistémica más allá del capitalismo global. Bogotá: Siglo del Hombre Editores, 2007.

QUIJANO, Aníbal. Colonialidad del poder, eurocentrismo y América Latina. In: LANDER, Edgardo (Org.). La colonialidad del saber: eurocentrismo y ciencias sociales. Perspectivas Latinoamericanas. Buenos Aires: Consejo Latinoamericano de 
Ciencias Sociales, 2000. p. 246-276.

Colonialidad del poder, cultura y conocimiento en América Latina. In: MIGNOLO, Walter. Capitalismo y geopolítica del conocimiento: el eurocentrismo y la filosofía de la liberación en el debate intelectual contemporáneo. Buenos Aires: Ediciones Signo-Duke University, 2001. p. 113-122.

QUIJANO, Aníbal; DUSSEL, Enrique; MIGNOLO, Walter. Una visión panorámica acerca de la teoría decolonial. In: CASTRO-GÓMEZ, Santiago; GROFOGUEL, Ramón (Org.). El giro decolonial: reflexiones para una diversidad epistémica más allá del capitalismo global. Bogotá: Siglo del Hombre Editores, 2007.

ROBERTSON, William. Historia de América. Burdeos: Pedro Beaume, 1827. 4 v.

SÁNCHEZ, Josué. Los europeos ante una estética olfativa indoamericana. Revista electrónica de Estudios Filológicos, Murcia, n. 11, 2006. Disponible en: https://www.um.es/tonosdigital/znum11/estudios/22-bellezaolfativa.htm . Acceso en 10 agosto, 2015.

SMITH, Adam. Lecciones de Jurisprudencia. Madrid: Boletín del Estado, 1996.

SOUSA SANTOS, Boaventura de. Una epistemología del Sur. México: Clacso-Siglo XXI, 2009.

TODOROV, Tzvetan. La Conquista de América: el problema del Otro. México D.F.: Siglo XXI editores, 2007.

VOLTAIRE. Estudio sobre los hábitos y el espíritu de las naciones. Buenos Aires: Hachette, 1959.

Recebido em: 27/09/2016 * Aprovado em: 05/01/2017 * Publicado em: 30/06/2017 